\title{
Can Angular Deformity Due to Sacrococcygeal Fracture Cause Permanent Impairment? : Current State and Problems in Korea
}

\author{
Dosang Cho \\ Department of Neurosurgery, Ewha Womans University Seoul Hospital, Seoul, Korea
}

Disabilities can emerge due to traumatic spinal fractures. In terms of sacrococcygeal spine, because of its unique anatomic structure with minimal movement, the possibility for it to have a disability is relatively low. In Korea, unlike most disability criteria, private insurance companies acknowledge angular deformities caused by vertebral fractures as disabilities according to their degree, so there were several cases where patients required compensation, arguing angular deformity caused by sacrococcygeal fracture, which in some cases led to legal conflicts. Except the Act Welfare of Persons with Disabilities which recognizes only severe angular deformity affecting internal organs as disability and the industrial accident disability evaluation which does not recognize coccygeal fracture as disability but rarely recognizes sacral vertebra deformity equivalent to compressive deformation, there is little or no case where angular deformity is recognized as disability. Given the impairment evaluation standards in social insurance, McBride system, American Medical Association (AMA) guides, and newly proposed standards by the Korean Academy of Medical Sciences (KAMS), the most contentious point in the general terms and conditions of private insurance is spinal deformity. To overcome controversy over disability evaluation, the private insurance sector is now applying criteria for axial skeleton to sacrococcygeal vertebrae through revision of standards. Under these circumstances, it is fair to recognize sacrococcygeal fracture as impairment in terms of the pelvis only when the fracture leaves serious deformity and neurological symptoms with clear relevancy. Though it may not be easy to develop accurate disability evaluation standards, improvement is necessary to remove any irrationalities and make the standards as objective as possible.

Key Words : Disability evaluation · Sacrococcygeal region · Spinal fractures.

\section{INTRODUCTION}

Traumatic spine fracture commonly occurs due to high-energy injuries such as falls, traffic accidents in young men. Thoracolumbar spine fracture is the most common, followed by cervical spine fracture, and sacrococcygeal spine fracture is the least common ${ }^{6,9,11)}$. However, in elderly patients, fractures usually occur due to relatively low-level falls, in which cases of sacrococcygeal spine become the second most common fractured area following cervical spines ${ }^{3)}$. Disabilities can emerge due to such traumatic spinal fractures. In terms of sacrococcygeal spine, because of its unique anatomic structure with

- Received : July 9, $2021 \cdot$ Accepted : September 7, 2021

- Address for reprints : Dosang Cho

Department of Neurosurgery, Ewha Womans University Seoul Hospital, 260 Gonghang-daero, Gangseo-gu, Seoul 07804, Korea

Tel : +82-2-6986-5461, Fax : +82-2-6986-3050, E-mail : 99drcho@gmail.com, ORCID : https://orcid.org/0000-0002-7116-9052

This is an Open Access article distributed under the terms of the Creative Commons Attribution Non-Commercial License (http://creativecommons.org/licenses/by-nc/4.0) which permits unrestricted non-commercial use, distribution, and reproduction in any medium, provided the original work is properly cited. 
minimal movement, the possibility for it to have a disability is relatively low. According to 6th edition of the American Medical Association (AMA) guides, sacrococcygeal spine is categorized as pelvis when determining its state of disability, and in Korea, there is no controversy in most disability evaluation standards. However, in private insurance terms, angular deformity is acknowledged as a disability caused by traumatic spinal injury. Therefore, there were several cases where patients required compensation, arguing angular deformity caused by sacrococcygeal fracture, which in some cases led to legal conflicts. Nevertheless, it is still hard to find literatures about disability evaluation due to sacrococcygeal fracture. This paper is to take a brief overview of diverse impairment assessment standards currently used in Korea with a snapshot of basic anatomical structure and function of the spine. It also aims to discuss impairment from sacrococcygeal vertebrae fracture, an issue that has been constantly debated.

\section{SPINAL DISABILITY ASSESSMENT}

As spinal disability assessment standards and their applications vary widely, doctors who have not been given sufficient learning opportunities through regular training courses tend to make different conclusions on spinal disability assessment. McBride system, unrevised since 1963, has been used in the courts and automobile insurance sector, while AMA system has been applied in the life insurance sector. In the meantime, workers' compensation insurance has adopted its own system through a series of amendments. The national pension service and national disability registration system have also applied respective evaluation criteria, causing confusion to doctors responsible for disability assessment in their line of duty ${ }^{5}$.

Here, the concept of insurance must be discussed first since it is an essential part of disability assessment. Generally, insurance is divided into social (statutory) insurance with public

Table 1. Classification of insurance system in Korea

\begin{tabular}{lll}
\hline & \multicolumn{1}{c}{ Social insurance } & \multicolumn{1}{c}{ Private insurance } \\
\hline Type & $\begin{array}{l}\text { National pension } \\
\text { Health insurance } \\
\text { Employment insurance } \\
\text { Workers' compensation insurance } \\
\text { Long-term care insurance for the aged }\end{array}$ & $\begin{array}{l}\text { Life insurance } \\
\text { Non-life insurance }\end{array}$ \\
Management & Government & \\
Obligation & Obligatory & Private insurance companies \\
Coverage & Mandatory basic cover & Optional \\
& & $\begin{array}{c}\text { Cover losses not covered by public insurance (examples : MRI, } \\
\text { upper-class hospital room charge, new medical technology, etc.) }\end{array}$ \\
\hline
\end{tabular}

MRI : magnetic resonance imaging

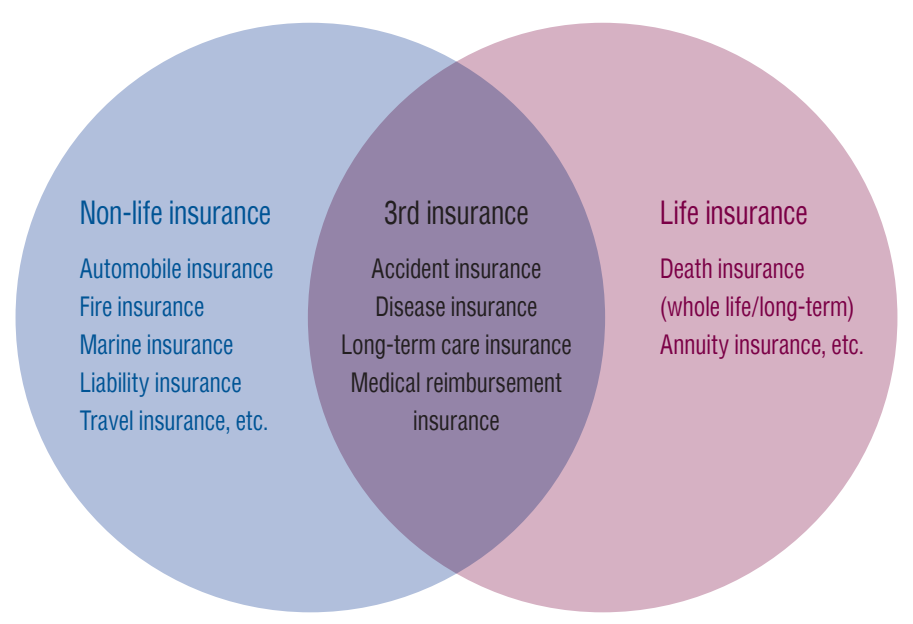

Fig. 1. Classification of private insurance. 
features managed by the government and private insurance managed by insurance companies (Table 1).

Publicly managed social insurance has its own standards by which doctors make adjudication at the time of assessment with little disagreement. In contrast, private insurance applies different standards at the time when customers purchase insurance. Moreover, private insurance is divided into life insurance, non-life insurance, and the third insurance, which respectively use disparate standards. Therefore, private insurance is more likely to result in errors and customer grievances in the process of disability assessment (Fig. 1).

If there had been fixed standards, disability assessment would not have been that much difficult, albeit standards varied by time and insurance classification. Currently, however, outdated McBride system, complicated AMA system, and even mixed opinions by doctors are used in combination, which adds to confusion in disability assessment to estimate compensation for impairments caused by traffic accident or potential impairment in the process of medical treatment.

The Korean Academy of Medical Sciences (KAMS) conducted research with relevant academic societies for years and published KAMS Disability Assessment Guidelines in 2011, commissioned by the Ministry of Health and Welfare (from 2007 to 2011) to establish the national disability assessment standards ${ }^{4)}$. With major errors discovered in the previous guidelines, KAMS released a revised version in 2016. Still, each sector uses different disability assessment standards it used to apply.

\section{TYPES OF SPINE DISABILITY ASSESSMENT}

\section{McBride system}

American orthopedic doctor Earl Duwain McBride wrote "Disability Evaluation: Principles of Treatment of Compensable Injuries" in 1936 and published its first edition in 1937. Since the sixth edition released in 1963, renewal has been stopped $^{8)}$. In Korea, McBride's evaluation system is still used in the courts and automobile insurance claims adjustment. However, it is too old to accommodate today's state-of-the-art treatments, and it applies outdated occupation coefficients. Despite the need for new standards, McBride system was not abandoned because of its relatively simple evaluation tables and familiarity.
Spinal disability is categorized into cervical, thoracic, thoracolumbar (thoracic vertebra No. 11 to lumbar vertebra No. 1), and lumbar vertebrae (lumbar No. 2 and below), for which different disability rates are applied. Furthermore, different occupation coefficients are used to adjust disability rates in assessment.

However, given the wide gap between occupations described in the McBride system and occupations of these days, courts are applying occupation coefficient 5 to spinal disability and occupation coefficient 3 to spinal cord injury.

\section{AMA guides}

The AMA published the "A Guide to the Evaluation of Permanent Impairment of the Extremities and Back" in JAMA in 1958 and submitted 12 additional assessment guides over the following 12 years. AMA integrated all the previous guides and released the first edition of disability assessment standards in 1971. Since then, through countless amendments, AMA released 6 editions including the latest one in $2007^{1)}$. Editions from 1st to 5 th covered the range of motion (ROM) in the spine as the most important disability assessment standard, while the 6th edition added disability assessment by diagnosis and excluded ROM.

\section{Life insurance disability evaluation}

In life insurance, disability evaluation standards went through numerous changes until they were revised into the life and non-life integrated version in 2005. The so-called "AMA system" that simply measures angles in ROM of the spine in most of the cases had been used previously. Some cases demand AMA-based impairment diagnosis even today, but actual AMA Guides excluded ROM measurement in impairment evaluation. Therefore, it is wrong to say that ROM measurement is AMA system. After a series of amendments, the life insurance sector tends to rule out ROM limitations. However, standards on angular deformity still remains as a point of contention and some insurance policies require ROM standards for underwriting according to the terms and conditions depending on the time of insurance subscription.

\section{Non-life insurance disability evaluation}

Just like life insurance, non-life insurance disability evaluation standards underwent a number of changes until its integration in 2005. Initially, disability was simply divided into 
deformity and limited ROM. However, these standards have been segmented with the addition of spinal disc herniation after 1998. Still, limitation of ROM was recognized as disability (which is a flawed standard) and vague concepts such as neurological symptoms and paresis of spinal nerve root increased confusion. Through the 2005 integration with life insurance standards, unreasonable ROM measurement was excluded and more specified standards on spinal disc herniation were suggested.

\section{Disability evaluation in the act on welfare of persons with disabilities}

In the Act on Welfare of Persons with Disabilities, spinal disability is graded mostly by the limitation of ROM. However, it does not apply limitation by direct ROM measurement, but predetermined ROM based on spinal motion segment to evaluate disability. Current evaluation standards may seem unreasonable since they do not take neurological symptoms into account. However, they may reduce noise in disability assessment. Moreover, evaluators do not evaluate disability grades directly, but diagnosis reports must be submitted to the National Pension Service, which then reviews and evaluates each case. Except life insurance, only the Act on Welfare of Persons with Disabilities included scoliosis and kyphosis in disability evaluation. However, serious angular deformity with scoliosis of 40 degree or above or kyphosis of 60 degrees or above may win grade 6 , which is the lowest evaluation grade.

\section{Disability evaluation in the national pension act}

The National Pension Act categorizes disability into grades 1 to 4 , and requires a document form for disability records. Since consultant doctors adjudicate the degree of disability for each case, there is no need to indicate disability grades. However, the Act requires doctors' descriptions on vertebral compression rates, electromyogram (EMG) results, fixation or fusion surgery, and neurological disability along with evidence. The Act applies ROM-based disability evaluation but uses predetermined ROM by spinal motion segment for disability evaluation as with the Act on Welfare of Persons with Disabilities.

\section{Disability evaluation in workers' compensation insurance}

Spinal disability evaluation in workers' compensation insurance has been improved through a series of reviews. While disability evaluation by the fixation segment resulted in many problems including excessive spinal fusion surgery in the past, it now allows limitation of ROM by fusion of motion segments, similarly to the national pension act. Previously, just as the current disability evaluation standards in life insurance, workers' compensation insurance specified spinal deformity by angular deformation. Currently, it evaluates disability based on spinal compression ratios, ROM limit by surgery (not by direct measurement of angles but by predetermined ROM limitation by motion segment), EMG, motor weakness, muscular atrophy, etc.

\section{ANATOMICAL STRUCTURE AND FUNCTION OF THE SPINE (VERTEBRAL COLUMN)}

The spinal column consists of 33 to 34 individual spinal vertebrae including cervical, thoracic, lumbar, sacral, and coccygeal vertebrae. It forms the spinal canal where the spinal cord and cauda equina pass. In the upper 24 vertebrae, consisting of seven cervical, 12 thoracic, and five lumbar vertebrae, each vertebral body is separated by a disc. On the contrary, it is known that the lower vertebrae consisting of five sacrum and 4-5 coccygeal vertebrae are fused to form one bone in adults. However, Tetiker et al. ${ }^{10)}$ reported that the coccyx is composed of three to five vertebrae, and it is rare that $2.8 \%$ of the coccyx is completely fused into a single bone and is divided into two to five bones.

\section{MORPHOLOGICAL FEATURES OF SACROCOC- CYGEAL VERTEBRAE (INCLUDING NORMAL CURVE OF COCCYGEAL VERTEBRAE)}

Cervical, thoracic, and lumbar vertebrae are known to be movable, whereas sacral and coccygeal vertebrae allegedly become fused together and immobile as a person grows up. However, according to research on coccygeal vertebrae by Woon et al. ${ }^{12)}$, all joints including the sacrococcygeal joint were fused in only three out of 112 adults in their spinal com- 
puted tomography (CT) scan. The sacrococcygeal joint was fused in $57 \%$ of coccyges, the first intercoccygeal joint in $17 \%$, the second in $61 \%$, the third in $89 \%$ of coccyges with four segments, and the fourth in all coccyges with five segments. In general, the sacrum can be said to be made up of four to six vertebrae due to the lumbarization of the first sacral segment or the sacralization of the lowest lumbar segment. However, it does not take much importance in medical terms.

Normally sacrococcygeal joint maintains an anteverted curve. However, according to Tetiker et al..$^{10)}$, the sacrococcygeal joint angle was retroverted in approximately $9 \%$ of cases. Normal anteverted angles in sacral and coccygeal vertebrae vary widely, 96 to 180 degrees and 152 to 179 degrees in anteverted and retroverted sacrococcygeal angles, and 77 to 180 degrees in anteverted intercoccygeal joint angles.

\section{MORPHOLOGICAL AND FUNCTIONAL CLASSIFI- CATION OF SACROCOCCYGEAL VERTEBRAE}

Angular deformity from fracture of sacrococcygeal vertebrae is seldom recognized as disability in social insurance or McBride system, while life and non-life insurance still recognize disability from deformation of normal curve of the spine. Especially whether to recognize deformation from normal curve of sacrococcygeal vertebrae became controversial. On this issue, the life and non-life integrated wordings, revised in April 2018, defined sacral (second sacral vertebra and below) and coccygeal vertebrae as pelvis, not spine (impairment classification on axial skeleton). Even in the 6th AMA guides, which is constantly being updated, included sacral and coccygeal vertebrae into pelvis. Unlike cervical and thoracolumbar vertebrae, the sacrococcygeal vertebrae have a limited ROM and a wide range of normal curve. All other disability evaluation standards, sacrococcygeal vertebrae are not included in the spine. Therefore, it must be rational to include them in the pelvis.

\section{DIAGNOSTIC TOOLS FOR COCCYX FRACTURE}

There are a few studies on coccygeal vertebral fracture. They rarely happen, and seldom require surgical treatment as conservative treatment can improve the situation in most cas- es. In sacrococcygeal vertebrae fracture, $24-70 \%$ cases reported a delayed diagnosis resulting from a missed timing of the initial X-ray $\operatorname{scan}^{2)}$. It is difficult to identify fractures due to kyphotic curvature of the sacrum and coccyx, complex structure of the surrounding pelvis and internal organs, etc. According to Maigne et al. ${ }^{7)}$, research on coccygeal fracture classification was conducted for the first time in 2020. The study found that most coccygeal fracture occurs in the first or second coccygeal vertebra and magnetic resonance imaging (MRI) was required to confirm a distal fracture. Birth injury mostly occurs in a distal area, and diagnostic tools such as bone edema diagnosis from an MRI scan were required to confirm the case.

It is easier to detect sacral fracture from a standard X-ray than coccygeal fracture given the small size of coccygeal vertebrae and overlying internal organs in the pelvis. The diagnosis of a coccygeal fracture can be estimated to some extent through examinations such as history taking, inspection, digital rectal examination, palpation on the injury site. Radiographic diagnosis is often ambiguous in CT, so it can be confirmed through additional MRI or bone scintigraphy.

\section{MEDICAL RELEVANCE OF ANGULAR DEFORMI- TY SUCH AS LORDOSIS, KYPHOSIS AND SCO- LIOSIS IN SACROCOCCYGEAL VERTEBRA WITH LITTLE MOVEMENT OF THE SPINAL SEGMENT}

Some cases in thoracolumbar vertebrae require treatment as the spinal curvature deteriorates or the spine deforms into an opposite curve due to injuries or degenerative diseases. However, it is difficult to find an abnormal curve in cervical and sacrococcygeal vertebrae except some extraordinary cases such as congenital deformities or tumors. Since sacral vertebrae are mostly fused as a single bone, deformation from sacral fracture hardly causes functional problems in the spinal column. Coccydynia from deformation of coccygeal vertebrae or nonunion of coccygeal fracture may require surgical treatment, but they basically form a kyphotic angle and have a wide range of normal angle. Therefore. It is not medically valid to diagnose deformation such as lordosis, kyphosis, or scoliosis in the sacrococcygeal vertebrae. 


\section{IS IT VALID TO APPLY THE SAME STANDARDS FOR ANGULAR DEFORMITY BY THE DEGREE TO THE SACROCOCCYGEAL SEGMENTS? : IN GENERAL TERMS AND CONDITIONS (SPINAL IMPAIRMENT CLASSIFICATION TABLE) OF PRI- VATE INSURANCE}

The cervical and thoracolumbar vertebra are mainly maintained in motion by the discs and the facet joints and may cause pain or neurological deficits due to angular deformity in daily life movements. However, since the sacrococcygeal spine has little movement and is known to improve with conservative treatment after trauma, it is not medically feasible to apply disability caused by angular deformation.

According to the research by Hanna et al. ${ }^{2}$, among $687 \mathrm{pa}-$ tients who visited ER and took an X-ray scan on sacrococcygeal vertebrae, only $8.4 \%$ (58 patients) of them reported abnormalities (fracture or suspected of fracture), and no one needed surgical treatment within 60 days. They concluded that X-ray scans at ER for sacrococcygeal vertebrae only have little clinical significance, hence no need for taking such X-ray scans. According to the study, upper sacral fracture that may cause neurological loss or instability had already been classified as high-risk group and actively treated with close examination on pelvic bones through X-ray or CT scan and surgeries. The research limited the subject to patients within 60 days after injury to find out cases that may require surgery for lower sacral and coccygeal fracture accompanied with instability, which rarely occurs.

Except the Act Welfare of Persons with Disabilities which recognizes only severe angular deformity affecting internal organs as disability and the industrial accident disability evaluation which does not recognize coccygeal fracture as disability but rarely recognizes sacral vertebrae deformity equivalent to compressive deformation, there is little or no case where angular deformity such as lordosis/kyphosis, scoliosis is recognized as disability. Sacrococcygeal vertebrae are anatomically different from cervical and thoracolumbar vertebrae and difficult to cause any particular functional disorder. Given this fact, it is not appropriate to apply disability evaluation based on angular deformation of common spinal fracture to sacrococcygeal fracture in general terms and conditions of private insurance. Rather, it would be much more rational to conduct disability evaluation by including sacral and coccy- geal vertebrae in the pelvic region as AMA disability evaluation standards do through numerous reviews and updates. Another reason is that sacrococcygeal vertebrae have a far wider angle than cervical, thoracic, and lumbar vertebrae.

\section{IN COMPARISON OF EVALUATION STANDARDS FOR SPINAL IMPAIRMENT (STANDARDS IN THE AUTOMOBILE INDEMNITY GUARANTEE ACT, IN- DUSTRIAL ACCIDENT COMPENSATION INSUR- ANCE ACT, STATE COMPENSATION ACT, GEN- ERAL TERMS AND CONDITIONS OF PRIVATE INSURANCE, ETC.), WHICH CASES SHOULD BE RECOGNIZED AS IMPAIRMENT AFTER SACRO- COCCYGEAL FRACTURE?}

According to Item 18 of grade 4 of injury classification in the Enforcement Decree of the Automobile Indemnity Guarantee Act, surgical treatment on pelvic fracture with an intact pelvic ring (including sacrococcygeal fracture) is subject to an indemnity limit of KRW 10 million. Permanent impairment classification included deformation of the spinal column, but there is no specific guidelines for application. The State Compensation Act, as with the Automobile Indemnity Guarantee Act, mentioned deformation of the spinal column but without detailed criteria. The Industrial Accident Compensation Insurance Act set forth specific impairment standards and recognizes deformation impairment, but only between grade 13 (equivalent to light deformation impairment with $10-20 \%$ vertebral body compression ratio) and grade 9 for serious nerve damage. Especially in the case of coccygeal fracture, deformation impairment is not recognized, and even fracture accompanied by neurological symptoms is classified as grade 14 , which is the lowest grade in the impairment evaluation.

To overcome controversy over impairment evaluation (which sometimes applied the same deformation standards to sacrococcygeal vertebrae in the past), the private insurance sector is now applying criteria for axial skeleton (pelvic bone) to sacrococcygeal vertebrae through revision of impairment evaluation standards. Under these circumstances, it is fair to recognize sacrococcygeal fracture as impairment in axial skeletons (pelvic bone) only when the fracture leaves serious deformation and neurological symptoms with clear relevancy. 


\section{CONCLUSION}

Given the aforementioned impairment evaluation standards in social insurance, McBride system, AMA system, and newly proposed standards by the KAMS, the most contentious point in the general terms and conditions of private insurance is spinal deformity. Basically, the spinal column has a wide range of angular formation. Therefore, without any medical information prior to injuries, applying the uniform angular deformity standards to evaluate disability is bound to be unreasonable and controversial. Though it may not be easy to develop accurate disability evaluation standards, improvement is necessary to remove any irrationalities and make the standards as objective as possible.

\section{CONFLICTS OF INTEREST}

No potential conflict of interest relevant to this article was reported.

\section{INFORMED CONSENT}

This type of study does not require informed consent.

\section{AUTHOR CONTRIBUTIONS}

\author{
Conceptualization : DC \\ Data curation : DC \\ Formal analysis : DC \\ Methodology : DC \\ Project administration : DC \\ Visualization : DC \\ Writing - original draft : DC \\ Writing - review \& editing : DC
}

\section{ORCID}

$$
\text { Dosang Cho https://orcid.org/0000-0002-7116-9052 }
$$

\section{References}

1. American Medical Association : Guides to the evaluation of permanent impairment, ed 6. Chicago : American Medical Association, 2007

2. Hanna TN, Sadiq M, Ditkofsky N, Benayoun M, Datir A, Rohatgi S, et al. : Sacrum and coccyx radiographs have limited clinical impact in the emergency department. AJR Am J Roentgenol 206 : 681-686, 2016

3. Jawa RS, Singer AJ, Rutigliano DN, McCormack JE, Huang EC, Shapiro $M J$, et al. : Spinal fractures in older adult patients admitted after lowlevel falls: 10-year incidence and outcomes. J Am Geriatr Soc 65 : 909-915, 2017

4. Kim YB, Lee SG, Park CW, Kim DJ, Park YK, Sung NJ, et al. : Korean guideline development for the evaluation of permanent impairment of the spine: proposal by the Korean Academy of Medical Sciences Committee. J Korean Med Sci 24 (Supple 2) : S307-S313, 2009

5. Lee KS, Doh JW, Bae HG, Yun IG : A design for assessment of sequelae and disability in patients with spinal injuries. J Korean Neurosurg Soc 28 : 670-674, 1999

6. Leucht P, Fischer K, Muhr G, Mueller EJ : Epidemiology of traumatic spine fractures. Injury $40: 166-172,2009$

7. Maigne JY, Doursounian L, Jacquot $F$ : Classification of fractures of the coccyx from a series of 104 patients. Eur Spine J 29 : 2534-2542, 2020

8. MCBride ED : Disability evaluation: principles of treatment of compensable injuries, ed 6. New York : Lippincott, 1963

9. Riggins RS, Kraus JF : The risk of neurologic damage with fractures of the vertebrae. J Trauma 17 : 126-133, 1977

10. Tetiker H, Koşar MI, Çullu N, Canbek U, Otağ I, Taştemur Y : MRI-based detailed evaluation of the anatomy of the human coccyx among Turkish adults. Niger J Clin Pract 20 : 136-142, 2017

11. Wang $H$, Zhang $Y$, Xiang $Q$, Wang $X$, Li C, Xiong $H$, et al. : Epidemiology of traumatic spinal fractures: experience from medical university-affiliated hospitals in Chongqing, China, 2001-2010. J Neurosurg Spine 17 : 459-468, 2012

12. Woon JT, Perumal V, Maigne JY, Stringer MD : CT morphology and morphometry of the normal adult coccyx. Eur Spine J 22 : 863-870, 2013 